Recebido: $11 / 11 / 2015$

Aprovado: 17/02/2016

\title{
Imprensa alternativa e desbunde: o Pasquim, a contracultura e os movimentos de esquerda nos 'Anos de Chumbo'
}

Natália Martins Besagio*

Resumo: O período denominado 'Anos de Chumbo' foi propício ao desenvolvimento da imprensa alternativa, responsável pela subversão dos ideais militares. Enquanto a imprensa oficial se alinhava ao poder, fazendo apologia à ideia do "Brasil, ame-o ou deixe-o", os jornais alternativos, como O Pasquim, utilizavam-se do humor como forma de burlar a censura, sendo associados ao movimento da Contracultura e da Nova Esquerda. Diante desse panorama, o presente artigo tem como objetivo abordar os aspectos de produção da imprensa alternativa, associando-os à contracultura de maneira a indicar os pontos de aproximação e distanciamento entre os mesmos. Além disso, através de uma abordagem cultural-gramsciniana, pretende-se analisar a imprensa alternativa enquanto um movimento inserido no contexto de emergência da Nova Esquerda no Brasil.

Palavras-chave: Ditadura; Contracultura; Imprensa alternativa.

Abstract: The period known as the "Anos de Chumbo" gave rise to the development of an alternative press responsible for the subversion of military ideals. While the mainstream press aligned itself with the regime, supporting the slogan "Brazil, love it or leave it", alternative newspapers such as "O Paquim" (The Quibbler), have used humor as a way to bypass censorship. Many such papers were associated with countercultural movements and the New Left. Faced with this panorama, this article aims to address particular characteristics from the production by the alternative press through associating them with countercultural movements in order to trace the points of convergence and of divergence between them. Moreover, through a Gramscian cultural approach this article intends to examine the Alternative Press as a movement within the context of the rise of the Brazilian new left.

Keywords: Dictatorship; Counterculture; Underground press.

\footnotetext{
* Mestranda do Programa de Pós-Graduação em História da Universidade Estadual de Maringá, linha de Política e Movimentos Sociais. E-mail: natalia.besagio@gmail.com.
} 
A abordagem de um determinado acontecimento histórico pelo viés cultural é tarefa um tanto árdua para o pesquisador das ciências humanas. Em primeiro lugar pela dificuldade de conceituar o termo cultura, tão abrangente quanto fluído. Em segundo lugar, pelo fato de que "a relação entre cultura e política não foi, em si mesma, uma questão central ou privilegiada no debate da esquerda" (DAGNINO, 2000, p.62). Ao historiador que se propõe tal atividade, deve-se levar em consideração o fato de que a cultura, por diversas vezes, foi considerada como domínio da imposição ideológica de uma classe sobre outra, constituindose como o campo da alienação.

A primazia do conceito de ideologia acabou construindo uma armadilha para os estudos culturais [...] Seu principal impacto foi impregnar o domínio da cultura de uma dupla negatividade. Em primeiro lugar, uma negatividade derivada do determinismo econômico, que retirou da cultura qualquer possibilidade de dinâmica própria [...] Em segundo lugar, a cultura foi aprisionada na negatividade no sentido de que as ideias, e a própria cultura, eram consideradas predominantemente como obstáculos à transformação social, que deveriam então ser eliminados nas massas e substituídos pelo "conhecimento verdadeiro" (DAGNINO, 2000, p.64)

A ruptura desta perspectiva, que relacionava a ideologia ao Estado e às classes dominantes se deu, em grande parte, por meio da teoria elaborada por Gramsci. De acordo com o teórico, os movimentos de caráter cultural teriam centralidade na análise dos processos históricos, não relegando-os meramente ao plano econômico, nem mesmo associando-os apenas às classes dominantes. Neste sentido, Rudé pontua que "para Gramsci, a ideologia se torna mais "liberada", e acrescenta ainda que "com isso abrem-se as portas para o estudo de modos de pensar alternativos, de classe 'média' ou 'inferior', que o marxismo tendeu a ignorar" (1982, p.21).

Diante desta perspectiva, não haveria uma ruptura com o poder vigente, mas uma subversão cultural da sociedade. Assim, segundo o conceito gramsciniano de transformação social, "a revolução não é mais concebida como um ato insurrecional de tomada do poder do Estado, mas como um processo no qual a reforma intelectual e moral é parte integral, em vez de, simplesmente, uma consequência possível”, como explica Dagnino (2000, p.67). A abordagem cultural proposta por Gramsci foi aplicada em formas menos estruturadas de pensamento que circulam entre as pessoas comuns, "uma mistura de folclore, mito e experiência popular cotidiana" (RUDÉ, 1982, p.21) e que, no presente artigo, tem como 
objetivo aplicar-se à análise da atuação da imprensa alternativa durante os denominados 'anos de chumbo'.

Assim, à primeira vista, seria inviável aplicar a teoria de Gramsci, voltada para a cultura da classe comum, à imprensa, uma vez que esta estaria vinculada aos detentores do poder. Não se pensarmos que, durante a ditadura, a imprensa alternativa atuou de maneira a subverter os padrões da imprensa oficial, vinculada ao regime militar e utilizada como meio de propaganda para as ações do mesmo. A proposta gramsciniana serve de base para abordar a produção alternativa dos jornais por meio do viés cultural, uma vez que muitos destes veículos não se enquadraram na esquerda ortodoxa e partidária, indo ao encontro do conceito de contracultura e dos diversos movimentos ocorridos na década de 1960. Sobre este aspecto, Queiroz (2004, p.231) afirma que "nas estruturas de poder da imprensa alternativa havia uma forte inspiração gramsciniana, entendendo os jornais [alternativos] como entidades autônomas, com o principal propósito de contribuir para a formação de uma consciência crítica nacional" e acrescenta ainda que, deste modo, "acabaram por criar um espaço público alternativo".

Desse modo, para a execução do proposto, faz-se necessário o estabelecimento de alguns parâmetros que norteiam o movimento da contracultura no Brasil para, posteriormente, traçar um paralelo com a produção da imprensa alternativa, mais pontualmente do jornal $O$ Pasquim, fundado em junho de 1969. Para tanto, empresta-se o conceito de Luiz Carlos Maciel, o "guru da contracultura brasileira" uma vez que, levando-se em consideração sua obra e sua trajetória, tornou-se uma das referências ao movimento contracultural, que eclodiu no Brasil em meados da década de 1960. Maciel destacou-se não somente pela produção de uma arte engajada, por meio do teatro, mas pela escrita da coluna Underground no jornal $O$ Pasquim, por meio da qual trazia à tona questões de caráter contraculturalista, como certas variantes do rock e os movimentos da Nova Esquerda, constituindo-se em figura central do grupo que se convencionou chamar de "desbundados".

\section{Contracultura e imprensa alternativa}

Contra o automatismo e a passividade do regime capitalista, o movimento contracultural foi mais expressivo nos Estados Unidos, onde angariou inúmeros adeptos ramificando-se em distintas manifestações, desde certas ramificações do rock'n roll até as passeatas pelo fim da Guerra no Vietnã. A palavra de ordem era negação. Negar o poder que 
engendrava guerras, que estabelecia tiranias e que sustentava o racismo. A política estadunidense, taxada de genocida por intelectuais, ativistas e clérigos, era alvo das manifestações contraculturais que, influenciadas pelo flower power e associadas ao movimento hippie, exigiam o fim dos conflitos e do consumo exacerbado, como explicam Dan Joy e Ken Goffman (2007).

A "geração Coca-Cola", com todas as suas frivolidades consumistas e seu controle burocrático, passou a ser alvo das críticas elaboradas por movimentos de caráter contracultural, que buscavam a ruptura com o modelo que até então lhes fora imposto, apresentando-se sob diferentes roupagens e despertando desafetos. Nesse sentido Maciel afirma que para os contraculturalistas "o conformismo - definido pelo marxismo como alienação e denunciado pelo existencialismo como existência inautêntica - é a essência do que se passou a chamar caretice”, principalmente após a revolução deflagrada na década de 1960.

A juventude, que culpava os próprios pais pela herança de uma sociedade controlada e apática, buscava agora libertar-se dos tabus que a prendiam. Acima da liberdade política e de expressão, os jovens almejavam a liberdade da alma. Nas palavras de Luiz Carlos Maciel

O rompimento das cadeias ideológicas permitiu o florescimento de uma nova visão política que proibia proibir e colocava a imaginação no poder. Esse processo foi fundamental para toda uma geração que, ao enfrentar corajosamente a repressão externa, era obrigada, por questão de sobrevivência, a atacar com energia suas repressões internas, a livrar-se delas, se possível. A política anarquista, no bom sentido, de 68, tinha uma dimensão espiritual. Nossa alma queria ser livre (MACIEL, 1987, p.81)

Tendo como pano de fundo a Guerra Fria, que dividira o mundo em dois grandes blocos antagônicos, um capitalista e o outro socialista, os movimentos contraculturais deste período buscavam a ruptura com os modelos estabelecidos, engendrando pensamentos transcendentalistas que negavam a sociedade do consumo, a propriedade privada e as intermináveis regras ao viver, ainda que para isto fosse necessário o uso indiscriminado de drogas e o sexo livre. Até mesmo os movimentos provenientes da esquerda, que pululavam diante da bipolaridade mundial, assumiram características completamente distintas dos seus congêneres de períodos anteriores, uma vez que procuravam romper com o partidarismo ou mesmo o autoritarismo que, por vezes, caracterizaram esta vertente política. Seus integrantes não desejavam pura e simplesmente a difusão de uma ideologia ou a identificação com um determinado segmento. Queriam apenas tomar um novo caminho, romper. 
No Brasil tais ideias tomaram corpo na década de 1960, apresentando perfis um tanto peculiares e adaptados à cultura tropical. Isto porque, o movimento contracultural caracterizou-se pela pluralidade de manifestações e, ainda que apresentasse traços comuns, desenvolveu-se de maneira diversa em cada região. A este respeito Cardoso atenta para o fato de que os movimentos contraculturais

[...] não foram homogêneos, apesar de apresentar questões comuns e ter um perfil jovem. A contracultura aconteceu como movimento preponderante nos Estados Unidos, embora traços dela tenham estado presentes em outros países. Os movimentos de caráter mais político também tiveram traços contraculturais, assim como os movimentos contraculturais que, embora rejeitassem fortemente as maneiras de fazer política de seus jovens contemporâneos, também se vim fazendo política a seu modo. Assim, 'mudar a vida' condensa uma diversidade de significados e esteve presente como ideal em vários lugares, tanto na práticas cotidianas como nos ideais sociais, políticos, culturais e éticos alternativos aos existentes (CARDOSO, 2005, p.98).

Nesse ponto vale ressaltar que as distintas manifestações contraculturais que ocorreram no Brasil, o fizeram apesar da ditadura e, não em decorrência da mesma. $\mathrm{O}$ movimento se desenvolveu primeiramente nos Estados Unidos e em alguns países da Europa, apresentando-se assim como um acontecimento de caráter universal, que adquirira traços de brasilidade quando em terras tupiniquins. "Ao contrário do que se chegou a proclamar, a contracultura se expandiu no Brasil não por causa, mas apesar da ditadura. Equacionar contracultura e ditadura é abolir o fato de que o underground foi um fenômeno universal", pontua Risério (2005, p.26). Para o autor, o movimento contracultural foi como um "rolo compressor" que passou por cima dos padrões de comportamento estabelecidos pelo regime militar, mas que não deixou de se alinhar às manifestações que, no mesmo período, eclodiram em todo o mundo.

E se a palavra de ordem era negar, a imprensa alternativa o fizera de maneira bastante contundente. E, neste ponto, os jornais de caráter alternativo, como O Pasquim, aproximaramse da contracultura, oferecendo-nos um viés cultural para análise das ações categorizadas como subversivas e que, de alguma maneira, contestaram os padrões impostos pela ditadura. Assim, a imprensa alternativa teria se constituído como um veículo de ruptura com o modelo vigente, desobedecendo não somente as austeras e violentas imposições militares, mas os próprios padrões de escrita e veiculação de informações. Não se enquadravam na direita, nem 
tampouco na tradicional esquerda. Não utilizavam regras de publicação, ou pauta, ou mesmo editorial, como acontecera com o Pasquim.

A "patota" era uma forma específica e original de organização de pauta, não burocrática e extremamente criativa. Reuniam-se em bares e relacionavamse com indivíduos iguais, discutindo cada edição de forma espontânea [...] Cada um já era muito bem informado e relacionado, o que levava a uma troca muito quente de ideias. Por isso O PASQUIM, sem ter reportagem nem sucursais, era um jornal sempre de grande atualidade. Na "patota", dava-se um processo de realimentação de ideias e de informações que não era mera soma de idiossincrasias, e também não precisava de hierarquia (KUCINSKI, 2001, p.107).

Nesse aspecto é importante ressaltar que, segundo Kucinski (2001, p.6), a imprensa alternativa dividia-se em duas categorias. A primeira predominantemente política, pedagógica e dogmática, com raízes fincadas no marxismo e nos princípios morais propostos pelo Partido Comunista, como o jornal Opinião. Já a segunda estaria mais identificada ao movimento contracultural, vinculando-se ao anarquismo, ao orientalismo e ao existencialismo de Jean Paul Sartre, como o fizera $O$ Pasquim. De acordo com o autor, "seus protagonistas, muitos deles antigos militantes de esquerda, haviam adotado o existencialismo como fuga instintiva do dogmatismo das esquerdas e da própria realidade opressiva do que como adesão a uma nova acepção de ser".

Diante desta perspectiva, é possível afirmar que os jornais alternativos não se identificavam com os tradicionais movimentos da esquerda, confluindo para o que se convencionou chamar de Nova Esquerda. Isto porque, ainda que seus integrantes fossem dissidentes de um marxismo ortodoxo, a Guerra Fria lhes fazia acreditar que tal modelo não se enquadraria em seus anseios, não mais voltados para a luta armada e a tomada do poder, mas para uma revolução que aconteceria dentro do próprio indivíduo e, depois, se estenderia para o restante da sociedade, provocando uma ruptura com os padrões éticos e morais que a ditadura havia imposto. Não era uma tentativa de usurpação, era uma revolução que, no sentido literal da palavra, colocaria a ética militar "de cabeça para baixo". Neste sentido, Sthephens (1998) afirma que, "para a contracultura o projeto era precisamente ir além dos limites das formas de política convencional ou 'disciplinar' para inventar, na medida do possível, uma linguagem completamente nova", devido à estreiteza das categorias marxistas tradicionais. 
Seguindo por este viés, a imprensa alternativa teria mais um ponto de intersecção com o movimento contracultural, não rompendo com padrões políticos e econômicos como o pretendiam os ideais revolucionários da esquerda, mas propondo um novo caminho a fim de subverter os valores impostos pelo regime. Rompeu com a tradicional esquerda e também com o jornalismo objetivo e supostamente imparcial emprestado dos norte-americanos. Assim, para reafirmar tal proposição, segue um estudo de caso onde a imprensa alternativa provocara uma ruptura, alinhando-se ao movimento da contracultura. Para tanto, toma-se por base a produção do jornal $O$ Pasquim, um dos jornais mais recorrentes no que diz respeito à produção alternativa.

\section{O Pasquim}

Coincidência ou não, foi também nos denominados "anos de chumbo" que a censura aos meios de comunicação tomou forma com a invasão e destruição de alguns jornais que ousavam colocar em pauta as falcatruas do regime militar. Foram alvos de violência e repressão tanto jornais de grande circulação como Última Hora e Correio da Manhã, quanto nanicos e panfletários como Opinião, Movimento, Em Tempo e O Pasquim. A esse despeito, foi reformulada, em 1970, a Divisão de Censura de Diversões Públicas a fim de que peças teatrais, filmes, programas de televisão, além de mídia escrita, passassem pelo crivo dos censores que consideravam subversivo tudo que atentasse contra a moral e os bons costumes, aliciando a juventude brasileira.

Enquanto slogans anunciavam "ninguém segura este país", a censura atingia seu ponto alto durante o período do milagre brasileiro, fechando portas e descendo a pancada. Isso sem falar do controle exercido sobre os meios de comunicação, que executaram manobras de manipulação de massa para divulgar a ideia de que o país caminhava de forma acelerada rumo ao pleno desenvolvimento.

Ao êxito econômico não correspondeu progresso político algum. Pelo contrário, entendeu-se que a ditadura era, se não a causa, indiscutivelmente a garantia da prosperidade. $\mathrm{O}$ controle da imprensa desempenhou um papel essencial na cantata desse "Brasil Grande" e na supressão dos conflitos que abrigava. Quando Pelé cabeceou para Jairzinho, esse processo de controle já estava concluído, depois de seis anos de truculências manhas e seduções (GASPARI, 2002, p.210). 
Navegando contra a maré, surgiu a denominada imprensa "nanica" que, de pequena, tinha apenas o nome. Dentre os semanários impressos em papel de jornal estava O Pasquim, precursor de um jornalismo inovador e irreverente. Criado em junho de 1969, em plenos "Anos de Chumbo", o jornal alcançou uma tiragem de 250 mil exemplares em apenas seis meses, como pontua Gaspari (2002). Segundo o autor, o semanário "sobreviveu a boicotes econômicos, censura, duas bombas e à prisão de toda sua redação. Fazia medo por engraçado."

Por intermédio de uma linguagem coloquial e carregada de gírias, o jornal abordava temáticas até então pouco discutidas pela grande imprensa, devido à censura e ao moralismo característicos de um governo militar, como pontua Petrini

\begin{abstract}
Inspirado no ideário da contracultura norte-americana, questões de natureza diversas foram trazidas à tona, muitas consideradas tabus pela sociedade conservadora, como, por exemplo, as drogas, o sexo, o feminismo, o divórcio, entre muitos outros assuntos. Assim, questões não somente vinculadas a fatos, mas conceitos e valores relacionados à política, ao comportamento da juventude e à crítica social, ao moralismo da classe média, à cultura, ao imperialismo, ao liberalismo e tudo que era possível perceber sobre a ditadura civil-militar, constituíam as principais pautas do jornal e suas abordagens se davam com a utilização dos mais diversos recursos de expressão, como textos, fotografias, desenhos, tendo o humor como um de seus aspectos mais marcantes. Críticas contundentes eram tecidas também ao capitalismo e ao stalinismo. Constituía-se um espaço para todos que se encontravam silenciados naquele momento, como artistas e exilados políticos. (PETRINI, 2012, p.26)
\end{abstract}

Diante das características gerais apresentadas pelo veículo que, procuram romper com o padrão tradicional da imprensa escrita, convém demonstrar em que aspectos se dá esse funcionamento e o modo como os mesmos aproximam a imprensa alternativa da ação empreendida pela contracultura. Para tanto, iniciamos com o caráter empresarial do jornal $O$ Pasquim ou, na verdade, a ausência de um caráter empresarial. Enquanto a grande imprensa pautava-se pelas regras de um modelo capitalista, cujo principal objetivo era gerar lucro, o "nanico" Pasquim não possuía estrutura de empresa, "que tem como corolário a insolvência financeira e a ausência da tradicional hierarquia das redações dos grandes veículos - dos quais muitos dos fundadores de jornais e revistas são originários", como explica Queiroz (2004, p.232).

Outra especificidade do Pasquim era sua organização em torno da "patota" o que, segundo Kucinski (2001, p.107), ocorreu pelo simples fato de que o "grupo não se via como

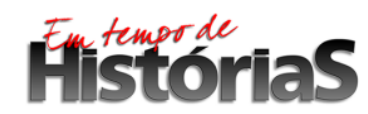


uma empresa, nem mesmo como uma redação convencional, mas como uma patota, um grupo de amigos que tinha prazer de fazer de suas relações pessoais o idiossincrasias, matéria de jornal”. Assim, destoando das regras estabelecidas pelas grandes empresas jornalísticas, não adotava pauta, nem tampouco linha editorial. Era um veículo plural, por meio do qual cada um dos autores se expressava de maneira singular, sem aparentemente seguir um mesmo perfil.

No jornal, cada autor marca sua individualidade no texto. De um modo geral os jornais costumam, através dos manuais de redação ou do copidesque, gerar uma média de escrita que os caracteriza. O Pasquim evitava esta aparente neutralidade formal. As padronizações na imprensa têm a função de fazer acreditar numa suposta visão objetiva da realidade: se todos escrevem igual, todos vêem (sic) igual. Ou seja, a visão parece neutra a objetiva. Já no Pasquim, cada autor tinha o seu estilo pessoal de escrita, todos eram subjetivos e impregnavam de pessoalidade o texto, isto era uma marca de sua influência existencialista (QUEIROZ, 2004, p.237).

Diante dessa exposição, exemplifico por meio dos conceitos de pauta e linha editorial a discordância da produção feita pela "patota". Segundo Nilson Lage (2001), a pauta se popularizou na década de 1950 por meio do jornal Última Hora, além de uma reforma editorial que seguiria os moldes norte-americanos. Assim, a pauta iria se constituir enquanto a técnica de redação que "daria o tom" das reportagens, selecionando o que deveria ser, ou não, noticiado, além de definir uma forma de abordagem para o conteúdo. Basicamente, seu objetivo era "o planejamento de uma edição [...] com a listagem dos fatos a serem cobertos no noticiário e dos assuntos a serem abordados em reportagens, além de eventuais indicações logísticas ou técnicas" (LAGE, 2001, p.34).

Mas nada disso fazia sentido aos "desbundados", que optavam por definir a temática de seus escritos conforme o gosto pessoal e, de preferência, na mesa do bar. Os jornalistas do Pasquim não escreviam seus textos a partir de um tema pré-estabelecido, nem sequer centralizavam as ideias ou decisões nas mãos de um editor, caracterizando-se com um jornal autoral que, por este motivo, aproximava-se do movimento da contracultura. Assim, o veículo rompia com os padrões de escrita previamente estabelecidos, tornando-se um espaço aberto à diversidade de opiniões em plena ditadura militar, ainda que algumas destas opiniões fossem conservadoras ou machistas, tema a ser abordado em um próximo trabalho.

Do mesmo modo lidavam com a linha editorial que, segundo os manuais de redação, tem como objetivo definir as diretrizes do veículo, seu posicionamento político, bem como sua abordagem dos fatos. A este respeito, Amaral (1987, p.137) afirma que "o jornal parte dos 
fatos, com reportagens, notas, entrevistas, e sustenta sua opinião com editoriais [...] nos quais satiriza, elogia, condena homens e idéias (sic), sempre de forma clara e lógica, a fim de atingir com mais facilidade as diversas classes de leitores". Desta forma, a linha editorial acaba por definir padrões claros de produção e veiculação de notícias, que norteia todo o trabalho da redação de um determinado jornal.

E, falando de padrões, não seria possível enquadrar nos mesmos a produção pasquiniana. O Pasquim não tinha editor chefe, nem tampouco linha editorial, seus membros "reuniam-se em bares e relacionavam-se com indivíduos iguais, discutindo cada edição de forma espontânea”, como lembra Kucinski (2001, p.107). Além disso, tinham como marca a transferência da oralidade para escrita, adotando uma linguagem coloquial e carregada de gírias como "pô" e "puts grila", buscando a proximidade com o leitor, ou seja, a efetividade da escrita. Segundo Queiroz (2004, p.239), “as páginas do Pasquim estavam recheadas desta oralidade, em todos os sentidos, seja nos artigos, seja nos desenhos e até mesmo na publicidade".

Diante dessas marcas de produção, é possível então traçar um paralelo entre o jornal $O$ Pasquim e a contracultura, termo que se aplica às mais diversas manifestações da década de 1960 e que também se fez sentir na área da comunicação. Além das colunas que abordavam diretamente a temática contracultural, o veículo apresentara uma forma um tanto inusitada de produção e veiculação de notícias, colocando em prática a premissa de que o importante era negar. Negar a ordem estabelecida, negar as ideologias políticas em sua forma tradicional e negar os padrões de escrita impostos pelos manuais de redação e tão caros à imprensa desde a década de 1950 e o alinhamento ao modelo jornalístico estadunidense.

\section{Conclusão}

Ao historiador cabe a tarefa de compreender um determinado acontecimento a partir da análise de uma fonte, lembrando-se sempre que esta pode lhe enganar ou então, não se enquadrar em um rígido padrão ou modelo teórico de explicação. Assim, ouso dizer que, abordar a história da ditadura a partir do ângulo de leitura d'O Pasquim, é levar em consideração sua pluralidade e diversidade, não tentando reduzi-lo a um determinado padrão, pois ele mesmo não o fizera.

Definir o veículo como imprensa alternativa de caráter contracultural seria um reducionismo pouco funcional às pesquisas sobre comunicação, história, ou qualquer outra 
área de pesquisa. Isto porque, sendo um jornal autoral que englobava distintos autores com opiniões as mais diversas, não poderia apresentar um ponto de vista homogêneo, sendo enquadrado enquanto movimento de esquerda ou então, difusor de contracultura. É óbvio que, diante da fonte, podemos encontrar os tons de uma esquerda "desbundada" e nada militante, ou então temáticas alinhadas ao movimento contracultural. Mas seria um desperdício definirmos um padrão de atuação ao jornal que sempre "deu de ombros” para as regras.

\section{Referências bibliográficas}

AMARAL, Luiz. Técnica de jornal e periódico. Rio de Janeiro: Tempo brasileiro, 1987.

DAGNINO, Evelina. "Cultura, cidadania e democracia: a transformação dos discursos e práticas na esquerda latino-americana”. In: ALVAREZ, Sonia; DAGNINO, Evelina; ESCOBAR, Arturo (Orgs.). Cultura e política nos movimentos sociais latino-americanos: novas leituras. Belo Horizonte: Editora UFMG, 2000, p.61-101.

GASPARI, Elio. A ditadura escancarada. São Paulo: Companhia das Letras, 2002.

GOFFMAN, Ken; JOY, Dan. Contracultura através dos tempos: do mito de Prometeu à cultura digital. Tradução de Alexandre Martins. Rio de Janeiro: Ediouro, 2007.

KUCINSKI, Bernardo. Jornalistas e revolucionários: nos tempos da imprensa alternativa. São Paulo: Edusp, 2001.

LAGE, Nilson. A reportagem: teoria e técnica de entrevista e pesquisa jornalística. Rio de Janeiro: Record, 2001.

MACIEL, Luiz Carlos. Negócio seguinte: Rio de Janeiro: Codecri, 1982. . Anos 60. Porto Alegre: L\&PM, 1987.

PETRINI, Paulo. Gêneros discursivos iconográficos de humor no jornal O Pasquim: uma janela para a liberdade de expressão. Londrina, 2012

QUEIROZ, Andréa Cristina de Barros. O Pasquim: um jornal que só diz a verdade quando está sem imaginação (1969-1991). História \& Perspectivas, n.31, p.229-252, 2004.

RISÉRIO, Antonio. Duas ou três coisas sobre a contracultura no Brasil. In: COELHO, Claudio Novaes Pinto. Anos 70: trajetórias. São Paulo: Iluminuras; Itaú Cultural, 2005.

RUDÉ, George. Ideologia e protesto popular. Tradução de Waltensir Dutra. Rio de Janeiro: Zahar Editores, 1982.

STEPHENS, Julie. Anti-Disciplinary Protest: Sixties Radicalism and Postmodernism. Cambridge: Cambridge University Press, 1998. Resenha de ADELMAN, M. O Reencantamento do político: Interpretações da contracultura. Revista de Sociologia e Política, n.16, p.143-147, 2001. 